\title{
More voice, less ventriloquism- exploring the relational dynamics in a participatory archive of mental health recovery
}

Submitted Version

Anna Sexton \& Dolly Sen (2018) More voice, less ventriloquism- exploring the relational dynamics in a participatory archive of mental health recovery, International Journal of Heritage Studies, 24:8, 874-888, DOI: 10.1080/13527258.2017.1339109

The archive of mental health recovery stories ${ }^{1}$ has been created in the context of Anna's PhD work to explore participatory approaches to building archives. The archive was built in response to the Wellcome Library's ${ }^{2}$ existing archive and manuscript collections around mental health, which have been predominantly built from the point of view of the asylum, the medical professional, the psychiatrist and the psychoanalyst. Within the existing archive collections, case notes of individuals enable us to gaze in at the patients within the system picking up details about pervading views on behaviour and treatment. However, what we can see, know, and construct about this past begins with us gazing through a heavily filtered lens controlled by those with power over the patient. Occasionally within case notes there are offerings penned in the hand of the patient, such as outgoing letters to family members or surviving examples of creative acts but these always and only have a place in the case notes because someone other than the patient has decided to keep them and place them in the surviving record. The archive of mental health recovery stories aims to show that individuals with lived experience can tell their stories, valued as having permanent significance alongside the stories told by the system, the institution and the medical professional, open now for anyone and everyone to explore.

The mental health recovery archive is based around the narratives of Anna Sexton, Dolly Sen, Stuart Baker-Brown, Andrew Voyce and Peter Bullimore. ${ }^{3}$ In the archive, each of us are represented as an exhibition that can be explored. Anna's section explores her role as instigator of the mental health recovery archive, her professional and research-orientated motivations for seeking to co-create the archive as well as her personal motivations relating to her own experience of post-natal depression. Dolly, Stuart, Andrew and Peter share a history of being diagnosed with serious mental health conditions and have all been part of the mental health system at some points in their lives. Their respective sections explore their individual experiences of mental distress, what has made a difference to them, their lives as they are now, and their stances on mental health. The archive grew from ideas sewn by Anna, connected to her PhD research. Anna set the initial vision for the archive as a collective space for individual expression around the theme of mental health recovery. Initially, Anna met individually on a one-to-one basis with the four other contributors but that gave way to running joint workshops as the development of the archive progressed, particularly when moving towards the archive's launch, which was a collective effort. Anna met Dolly, Stuart, Andrew, and Peter after making contact with the editor of a book of mental health recovery stories. It was the editor of that volume that put Anna in touch with the four contributors. Dolly, Stuart, Andrew and Peter therefore knew each other through past collaboration as well as through various mental health networks, but were only loosely connected to one another at the start of the project. This

\footnotetext{
${ }^{1}$ The mental health recovery archive can be found at: https://mentalhealthrecovery.omeka.net/exhibits ${ }^{2}$ The creation of the mental health recovery archive occurred in the context of Anna's PhD research which was funded by the Arts \& Humanities Research Council under the Collaborative Doctoral Award Scheme. Under this scheme, Anna had the Wellcome Library as an institutional host alongside University College London. For background information on the Wellcome Library visit: http://wellcomelibrary.org.

${ }^{3}$ All of the contributors to the archive have given their permission to be named in this article.
} 
article focuses on the development of the relational dynamic within Dolly and Anna's participatory relationship. For a broader exploration of the enactment of the participatory process, with perspectives and reflections from all the contributors, see Sexton (2016). ${ }^{4}$

Anna came to the project as an archivist with years of experience working with individuals and communities in archival spaces, and as a PhD researcher interested in using participatory methodology as a means of disrupting the power relations that can sit within and around archives. Dolly came to the project as an artist, film-maker, mental health consultant and trainer with lived experience of surviving the mental health system, interested in using the creation of the archive as a means of disrupting the dominance of the psychiatric narrative of mental health and illness. The article is built from our shared experience of using participatory methodology to build the archive of mental health recovery stories. It seeks to examine the nature of the relational dynamic between us which moved from a collaborative partnership towards friendship in the course of constructing the archive (practice) and critically reflecting together on its development (research).

The article has been constructed by interweaving our personal reflections on the shared process. The aim has been to use self-reflexivity as a method for exploring the benefits, challenges and complexities of taking an emotionally engaged and personal approach to participatory research. In particular, the article seeks to explore the role that our friendship played in enabling us to build affinity between us whilst simultaneously acknowledging and working with our differences; including confronting asymmetries in our positions and privileges.

The article concludes with Anna's reflections on the benefits and residual complexities inherent in basing a participatory approach around friendship, with thoughts on the transferability of the adopted relational dynamic to other contexts of practice and research, including its fit with shifting epistemological approaches being adopted in the recordkeeping field. This is followed by a final response from Dolly which reinforces from her perspective why embedding friendship into participatory methodology was vital in enabling a deeper and richer experience of joint research and practice.

\section{Dolly - why I participated in the archive of mental health recovery archive}

I haven't told my story yet in psychiatry. Mental health services read their script, I read my script, and nothing of any deep meaning is exchanged. Anna has talked about how most of the archives that depict mental health lived experience are filtered by mental health professionals, but that is like lions representing bird song in roars. Why should the hunters give the hunted's history? Why should the people who've never visited a land be that country's prime historians? How can we tell our true stories when our words are seen as sickness? The mental health archives at the Wellcome Library, as they stand, have observable data of inobservable worlds. That had to change. So that's why I participated in the archive of mental health recovery stories, to attempt to address that. The way I did that was to tell my story and to challenge the power psychiatry has. I wanted my section in the archive to show the dollyness of dolly. You do not see the dollyness of dolly in my psychiatric medical notes. Would working with Anna enable that process? Would she actually meet Dolly, the human being?

\footnotetext{
${ }^{4}$ This article is based on a joint presentation given by the two authors at the Community Informatics Research Network's 12th Conference, 'Privilege, Information, Knowledge \& Power', 9-11 November 2015, Monash Centre, Prato, Italy. Due to limited funding, only two out of the five contributors to the archive of mental health recovery archive could present at the conference which is reflected back in the limited co-authoring in this piece.
} 


\section{Anna - on methodology}

As an archivist I am committed to developing archival practices that challenge the lines of authority and control sitting around archives as sites of knowledge (re)production. As an academic, I am committed to developing modes of research which reflect on and transform the boundaries of who gets to shape academic discourse and on what terms.

Using the label 'participatory' has been my way of locating and grounding our work. In this section I want to articulate more precisely where I place the process we shared in relation to participatory methodology, and how the type of stance we pursued opens a space for a particular form of relational dynamic to develop that might be described as friendship.

I place the practice and research wrapped around the creation of the mental health recovery archive under the umbrella of 'Participatory Action Research' (PAR)..$^{5}$ The origins of PAR are rich and diverse, and the methodological approaches it embodies arise from a 'melting pot' of traditions, theories, and fields (Reason and Bradbury 2001, 3). A narrative on PAR can be formed under the lens of the contemporary critique of positivist science and the subsequent movement towards new epistemologies of practice (Reason and Bradbury 2001, 3), equally PAR's emergence can be framed in relation to the rise of liberation movements in the 1960s and 1970s and the emergence of activist scholars who sought to find ways to make their research relevant to contemporary social issues (Billies et al. 2010, 279). In the vein of the latter, the tenets of PAR are often infused with the pedagogical ideals of pioneering liberatory educators such as Freire $(1972,1976)$, and it is not uncommon to find Freire's notion of conscientizacao used as a means of highlighting the importance of building critical consciousness amongst participants within a given process. Instigations of PAR, like ours, that are influenced by Freire's ideology seek to challenge the notion that knowledge exists 'out there' to be accumulated, by focusing on valuing the experiential knowledge that participants carry with them. In this way, PAR methodology has become somewhat synonymous with the ideals of co-operative learning in which the experience and expertise held by co-participants becomes the basis for action (Billies et al. 2010, 279). What enables our research and practice to be described as a form of PAR is that it is grounded, first and foremost, in a socio-political agenda orientated around transformative liberation for those involved. We fall in line with the tenets of PAR in our commitment to privileging the voices and lives of participants as guiding and informative tools for producing both critical theory and social and individual change, and we have echoed the sentiments of PAR through our commitment to pay careful attention to the fluid and changing dynamics of power underpinning our participatory process (Baum, MacDougall, and Smith 2006).

The participatory dynamic between us has deepened as we have walked together through the process. At first I sought to create a relatively hard division between the creation of the archive and the research process sitting around it, so that the former could be 'participatory' and the latter could still follow the normative structure of a PhD in which I would be the singular researcher. This division became untenable as the process progressed. Paying critical attention to the power dynamics within the archive alonside the contributors meant that the participants were always and already contributing to my PhD as co-researchers. In recognising this more fully, I began to capture our collaborative inquiry through audio recordings of our discussions. As I moved into writing, the challenge became how to acknowledge the joint aspects of our knowledge production from within

\footnotetext{
${ }^{5}$ For an exploration of my growing understandings of what it means to be participatory, and my movement from theory to practice see Sexton, 2016.
} 
the normative 'single author' model of PhD research. The answer was to push into and against that model through the inclusion of large portions of our joint conversations in my thesis.

Our approach to paying critical attention to the power dynamics circulating within our participatory process has been shaped by Foucaldian notions where power is constituted not as something concentrated (or as a commodity to be held, seized, divided or distributed) but as a decentered and ubiquitous force (Kesby 2005, 2038). In this formulation power 'is not inherent within powerful subjects but dispersed throughout the complex networks of discourses, practices, and relationships that position subjects as powerful and that justify and facilitate their authority in relation to others' (Clegg 1989, 207 in Kesby 2005, 2038). This power is not 'absent unless being exercised' but is constantly at work in the fabric of daily life and social interaction (Kesby 2005, 2038). The implication is that if it is everywhere (and its permeation effects all social relations) then even participatory, emancipatory and anti-opressive practices inevitably and unavoidably are instigated in continuing and overlapping forces of domination. We have therefore sought to consider, from within the process, the complex interplay of structure and agency that has continuously shaped the realms of the possible in the specificity of our context, as all of our 'freedom to' is held and bounded in ongoing inter-related processes (Eyburn and Ladbury 1995). We have been attentive to laying bare the differences in our starting points, as well as the asymmetries in our relative positions and privilege, and the extent to which these asymmetries have been transformed through the creation of the archive of mental health recovery stories. Lykes and Coquillin suggest that this kind of 'coreflection' depends on the cultivation of a relational space that is capable of handling constructive dissent. They speak of fostering 'safe enough' spaces 'that strive to be inclusive and supportive' whilst at the same time enabling engagement in 'reflective critical practices that problematise the matrices of power, privilege and domination that circulate among us and in our social worlds' (2007, 301). Dolly and I have cultivated such a 'safe space' with each other, and we have both tended to reach towards the word 'friendship' to describe the movement of our relational bond.

Friendship is a relational stance that we are all familiar with, yet its dynamics are difficult to pin down. Its stable characteristics are that it is a voluntary relationship (Weiss 1998), that does not rely on kinship or the law for its establishment (Tillmann-Healy 2003). In view of this, friendship is often viewed as lacking in normative rules (Rawlins 1992, 9). Friendship is characteristically developmental, it passes though stages that may begin with role-limited interaction in a narrow context, which then grows and deepens into a more intimate relational tie where we become more 'truly present' with those we describe as friends 'meeting one another in our full humanity' (Tillmann-Healy 2003, 732). Friendship is built and sustained through interaction; for friendship to function there must be degrees of liking and respect running through the relationship, infused with trust, and an ethic of caring. Dolly and I certainly had these characteristics in our relationship. Yet, crucially, what establishing a friendship enabled us to have was an 'affective tie' that was resilient enough to enable us to address the 'dialectal tensions' (Tillmann-Healy 2003, 730) sitting within both the participatory process we have shared, and our relationship with one another. In friendship we found a robust interpersonal relation in which we could tackle head on the complex circulation of power between us, and the process we shared. It enabled us to meet each other in the middle of our sameness and our difference. To articulate, and then negotiate, what brought us together in the process and what kept us apart, within the assurance that our mutual affinity and respect would carry us through what may have been more troubling interpersonal exchanges, had we not cultivated such a strong bond.

There is an affinity between how Dolly and I see our friendship functioning, and Tillmann-Healy's argument that friendship between participants within a research processes can operate, in and of 
itself, as a method of inquiry. It is possible to suggest that it was in the embrace of the 'practices, the pace, the contexts and the ethics of friendship' that we were able to cultivate a form of practice and research that was 'open, multivoiced and emotionally rich' $(2003,734)$ yet stable, resilient and robust.

\section{Dolly - on methodology}

I don't know the standard methodologies of archivists or information specialists. I only know the methodology of being ostracised, demonised, disempowered and isolated because I am labelled mad. I have no intention in maintaining the status quo that keeps me ruined. I am only interested in challenging inequality; in something that has a socio-political agenda, and there is no more dangerous methodology than friendship in having the power to do that. More than object, more than subject, but a world opened because humanity has entered it.

\section{Anna - on being human}

I find resonance with Hailey's writing on participatory practice in a development context in which he explores the benefits of strong inter-personal relationships between facilitators and community members. Hailey advocates for participatory approaches that are not based on formulaic, structured relationships but on personal interactions that foster continual, reciprocal, mutual dialogue. He warns that these relationships are open to criticism, not least because they carry the risk of being 'easily manipulated by educated, articulate individuals whose power is derived from their access to funds, political contacts and new technologies' $(2001,101)$. He acknowledges the fact that there is potential for these relationships to act as a façade that enables cynical manipulation and paternalism. Yet he points to and seeks to uphold cases in which the relations sought are genuine, leading to effective sustainable joint working. Hailey sums up his thoughts on relationships in participatory settings by suggesting that they work when fused with degrees of affection and friendship $(2001,101)$. From a different perspective, in an exploration of participatory approaches in health contexts, Heckler and Russell seek to advocate for the centrality of 'positive affect and mutual liking' as the underpinning dynamic for establishing 'productive partnerships' (2008, 331). They surface a tendency in the literature around collaborative working to reduce complex inter-personal relations to a single characteristic such as 'trust', 'openness' or 'inclusiveness' that is then explored through an assessment of project structure rather than embodied interactions between people. Heckler and Russell recognise that this is in part related to the difficulty in pinning down the interpersonal characteristics of dynamics that foster positive means of co-production, yet they also surface the tendency in their field to see relationships in instrumental rather than in affective and embodied terms. They conclude with the radical suggestion that it is the depth and strength of the 'personal relationship and emotional engagement' that will ultimately make or break collaborative working $(2008,350)$. I believe my/our experience of being 'participatory' resonates with, and directly feeds into these perspectives.

\section{Dolly - on being human}

Our biographies change dependent on the other biographies we are surrounded with. One of the things psychiatry gives the people that go through its system is a deep sense of shame that they were disgusting enough to be sensitive to trauma or the brutalisation of their situation in life. Anna had no such agenda. She wanted to hear my story without bringing shame or pathology into the equation. Anna was professional but kind, warm and approachable. Not expert in the disempowering sense of the term, but professional in the sense that she knew about archives. But she did what very few professionals do in mental health, she shared her life with me, in talking about 
her family, for example. She also did something that allowed trust and authentic disclosure: she made me the mental health expert and the voice of my story, whilst offering support and guidance in the archival process. There was nothing to tell me that my guard should go up. From the start it was an open, fluid relationship. We had a lot of fun, and we ate a lot of cake!

\section{Anna - on relational ethics}

The starting points of all new relationships are different. It is not always straightforward to establish open, transparent, effective communication or initially positive relational possibilities with those we are coming together to work with in participatory settings. However, in the specificity of our localised context, the trajectory of our relationship did not overtly involve negotiating a relational movement from distrust to trust, though there were insecurities, niggles, and worries in the early stage, as with all new relationships. In our case, our coming together felt rapidly optimistic. We relatively quickly developed a shared underlying understanding between us of the possibility and likelihood that we would go on to trust each other.

Christopher et al. tie ethics and trust closely together, drawing out from their experiences of doing participatory work, five key features in collaborative research that help foster trusting relationships:

(1) acknowledge personal and institutional histories, (2) understand the historical context of the research, (3) be present and listen to community members, (4) acknowledge the expertise of all partners, and (5) be upfront about expectations and intentions. $(2008,391)$

Certainly, a similar drive to foster transparency and openness was there in our initial meetings. We spent time discussing the academic frame sitting round the archive/research, we explored the institutional link to the Wellcome Library, we acknowledged aspects of our lives and experiences that were shaping our entry into the process, and we had a continual conversation about what we were aiming for in creating the archive. However, although these principles are important in the establishment of trust, it is more complex and intricate then the establishment and enactment of ethical protocols to drive a process. Philosophers of trust have drawn out its affectual characteristics (see Baier 1986). Jones suggests that trust is 'an attitude of optimism that the goodwill and competence of another will extend to cover the domain of our interaction with her, together with the expectation that the one trusted will be directly and favourably moved by the thought that we are counting on her' $(1996,4)$. This resonates with the goodwill that infused our meetings even in the early stages, but it also points to the underlying element of obligation and responsibility that a trusting relationship engenders in both parties (Nickel 2007). Making the choice to trust someone to fulfil their obligations creates a vulnerability, and introduces an element of risk for the truster. To trust is to open yourself to the potential for betrayal as brought out by Holton - 'When you trust someone to do something, you rely on them to do it, and you regard that reliance in a certain way: you have a readiness to feel betrayal should it be disappointed, and gratitude should it be upheld' $(1994,67)$. Holton goes on to suggest that this range of reactive sentiments is a result of adopting 'the participant stance' $(1994,68)$. Therefore, when we come together as collaborators in a shared endeavour we have made the decision to trust each other to some degree. I would suggest that in a trusting collaborative relationship, the roles of truster and trusted are not fixed one-way positionalities. In our case, we were tied by degrees of obligation and responsibility towards each other in the fulfilment of our respective roles, and in this way we were both simultaneously 'truster' and 'trusted'.

Spandler and Stickley identify the key quality of compassion as a motivation to be caring and sensitive in our relation with others. This involves being able to be moved by distress, and being able 
to tolerate distress and understand it $(2011,557)$. This is vital because 'human beings are a profoundly social species who depend on the safety, care and support, affection, and encouragement of others to survive and thrive' $(2011,557)$. Acting out of compassion therefore involves fostering an active empathic presence, or what can be described as a 'being with', which is essentially an adoption of a stance that seeks out an understanding and appreciation of a person's unique way of being in the world $(2011,559)$. I was deeply moved by listening to Dolly sharing her experiences of abuse and psychosis. I felt, to the degree that it was possible for me to do so, her pain, her hurt and anger, as well as her optimism and hope. Yet, the point I want to make here is that an empathetic, compassionate stance has also always been a two-way relational dynamic between us. As I have shared aspects of my own experiences with Dolly - the moments that have shaped and defined me, my hopes, hurts, vulnerabilities, and strengths she has reciprocated with empathetic understanding. We name our relationship as friendship because we recognise that we have been moving towards the development of an 'affective tie' (Rawlins 1992) in which we expect 'honesty, respect, commitment, safety, support, generosity, loyalty, mutuality, constancy, understanding, and acceptance' from each other (Tillmann-Healy 2003, 731). There are of course boundaries around our interpersonal connection, but these boundaries have been critically and reflexively negotiated, pushed upon and extended as our relationship has deepened. We now know each other in multiple roles - as collaborators working together on the creation of the archive, and as co-researchers and co-authors, but also as partners to loved ones and the various relational stances we carry within our respective extended families.

The decision to invest deeply in a personal connection with Dolly and the other contributors must be understood in relation to the mental health related subject matter contained in the archive, and the normative pattern of relating between professionals and service users within the mental health system which we were able to stand away from to operate on different relational terms. ${ }^{6}$ Kathryn Church is a Canadian academic and mental health practitioner who has worked closely with the Psychiatric Survivor Movement in her own country. She talks about her experiences of researching and advocating with the Psychiatric Survivor Movement. She highlights the fact that in these contexts, psychiatric survivors, by virtue of their position as 'expert by experience', are continually expected to participate through personal disclosure because the survivor's legitimacy is accepted on the basis of their personal experience. In situations where 'survivors' and 'professionals' seek to work together on an equal footing the expectations around disclosure are asymmetrical: one has little choice but to disclose, whilst the other is free to compartmentalise 'public' and 'private' because their expertise is predicated on different grounds. The professional's right to 'compartmentalise' speaks into, and can reinforce, unequal power relations. It is therefore detrimental to the development of mutual understanding and respect $(1995,67)$. Church draws on Rockhill to suggest that it is 'not until we begin to talk out of our own dark recesses that we can appreciate fully the risk for others as we, with the best of intentions, ask them to open up for us' (Rockhill 1987, 13 in Church 1995, 67). My decision to embrace our developing friendship, and move with the rhythm of our relational tie into a more personally disclosive relational space, was shaped by my awareness of the power asymmetry that such a movement would be able to address and push against.

Different contexts across practice and research will demand a different approach to negotiating the degree of interpersonal connection between participants. Participatory contexts, where there is a

\footnotetext{
${ }^{6}$ It is important to emphasise here that our collaboration was undertaken outside, and at a distance from the mental health system. This made enacting our chosen relational dynamic more straightforward in that there was no expectation that our interaction was in any way part of a mental health care pathway of any kind.
} 
commitment to processes of co-reflection, may provide what seems like a natural opening to pursuing deep affective ties between participants. However, it is precisely because of the proximity between participants engendered in co-reflective processes that the negotiations of boundaries needs to be carefully considered. Friendship cannot be demanded or expected at the beginning of a co-reflective process undertaken in a participatory context. Equally, however, there are cases like ours, where its development does not need to be feared or resisted. Managing participatory relationships demands a critically attentive and continual negotiation around 'how private and how candid we will be, how separate and how together, how stable and how in flux' (Tillmann-Healy 2003, 732). There can be no 'one size fits all' establishment of where the boundaries of disclosure and involvement with participants should lie. There are many contexts where developing deep affective attachment, and investing in personal disclosure (to the extent that we have done) will be inappropriate movements. In the context of PhD research, the degrees of personal disclosure and emotional investment undertaken by students must be carefully weighed up by PhD supervisors, who have a duty of care towards their students. The level of the students' experience in operating in research contexts involving individuals and communities will play a part in establishing the rules of engagement. In my PhD supervisions, the evolving relational dialectics surrounding my work were continually surfaced and jointly interrogated. I had previously worked with my principal supervisor on a range of community heritage projects, and came to my PhD with years of experience developing relationships with individuals and communities around the archive. This helped to establish a degree of trust in relation to my level of experience and capacity to make sound judgments. Throughout the process, I found the oversight of my PhD supervisors, offered a welcome additional relational space in which the implications, complications and consequences of the relational stance I was developing with the participants, could be collectively worked through.

\section{Dolly - on relational ethics}

It is quite easy to connect with someone who cares for you, and doesn't think shame should be in the equation. Working with someone with little preconception as to how to work with survivors except to come to it from a position of empathy and intelligence was so palpable, so I see that as a necessary precondition. I don't think you even have to know what the person's condition entails beforehand. It was framed as: what works for you? How shall we work when things get difficult?

\section{Anna - negotiating similarities and difference}

The coming together to form shared perspectives and goals was an important aspect of our relationship. Yet, in the coming together there has always been the need to recognise and respect the separations and differences between us, and those differences cannot be glossed over by a claim to either friendship, solidarity or comradeship. I stand on the margins of the mental health system. I have not had to survive its abuse and cruelty. I cannot claim to share the same ground as Dolly. Kathryn Church notes this irreconcilable separation in her own experience by saying that she 'felt with great clarity the degrees of separation' which made her different from those within the survivor movement that she was working alongside, and which made her knowledge of survivors different $(1995,68)$. Quoting Ellsworth she says that:

I brought a social subjectivity that has been constructed in such a way that I have not and can never participate unproblemmatically in the collective process of self-definition, naming oppression, and struggles for visibility in the face of marginalization engaged in by position(s) I do not share. (Ellsworth 1989, 309 in Church 1995, 68) 
This resonates with what I would describe as a tension between the need to forge a common interest and build solidarity around shared goals and similar human experiences, whilst recognising and finding a way to work across the continuing separation between our positions in the coming together. These degrees of separation are about the ways in which the totalities of our life experiences lead us to a different knowledge and a different perspective. This recognition of difference is one that must take into account my separation as a 'non-survivor'7 from Dolly, Andrew, Stuart and Peter, as well as all of the ways in which Dolly, Andrew, Stuart and Peter are separated from each other. Creating the homogenous category 'the contributors' continually negates all the ways in which they are not the same. Negotiating the 'politics of difference' means confronting the multiplicity of difference - to trouble the 'false universals' (Mouffe 1992) that place all survivors, or service users, or voice hearers as universally the same or universally different (Moosa-Mitha 2005). For me, this has meant learning to look twice into my own uses of 'othering' categories. To be difference-centred is to adopt an active recognition that I cannot know, share or speak on behalf of knowledge that emanates from situations and positions beyond my own experience. It also requires learning to trouble my tendency to universalise what is 'other' to me. It is to learn to engage in mutual dialogue in which there is a reciprocal commitment to listen, and in the listening, to resist reducing one another to instances of abstraction (Lugones and Spelman 1983, 581).

The complexity and resulting dissonance in confronting and negotiating difference has been forcibly brought home to me at various points in the construction of the archive of mental health recovery stories. In my relationship with Dolly, I can surface this in relation to my awareness that Dolly was at one point participating in creating the archive while dealing with the threat of homelessness. This stark fact has caused me to understand deep within myself that our differences 'are not just discursive or theoretical: they are material, embodied and political' (Delhi 1991, 63 in Church 1995, 69). What is the ethical response to this difference? I know how I felt about it at the time. I felt angry, and to some extent guilty in my deepening awareness of my own degrees of privilege. I also felt despairing, to some extent, because the archive might aspire to enact a degree of transformation, but it was doing nothing to touch the immediate issues and struggles that Dolly was facing at the time of its creation. Yet those feelings became problematic in their tendency to place Dolly in the position of victim. How could I acknowledge Dolly's reality in a way that wasn't translating into a desire for 'mastery, heroism, and the wish to rescue'? (Lather 2007, 33) The only way was and is to acknowledge our differences as part of our friendship. To foster a commitment to name and deal with our differences, to talk to each other about these issues, and through that find ways to work in and through the things that keep us together and the things that keep us apart.

It has felt to me, particularly when I reflect on my relationship with Dolly, that in seeking to negotiate sameness and otherness, a productive tension has been created in our relationship by refusing to occupy either space too resolutely. In keeping with Han, I would suggest that we are working towards refusing to negate our differences. In practice this has meant recognising the limits to which the distances between us can be sublimated through empathetic understanding $(2010,14)$. It has been a case of seeking that third relational space in between 'same' and 'other' (perhaps even between friendship and enmity) in which there is critical reflection on as well as constant negotiation between 'fluctuations of distance and proximity' (Han 2010, 14).

Mentinis argues that to conflate friendship with comradeship is to 'negate the anarchic character of friendship' closing up the possibility of seeing friendship as a positive form of social experimentation,

\footnotetext{
${ }^{7}$ Dolly identifies as a 'survivor' of intervention from psychiatry and the mental health system. Anna, by distinguishing herself as a 'non-survivor', is highlighting that she has never experienced similar intervention.
} 
that resists the normative rules of relating $(2015,74)$. Friendship can break us out of institutions that emphasise commonality and can enable us to break away from ingrained patterns of social interaction that dictate who usually relates to whom and on what terms (Mentinis 2015, 74). Similarly, Lynch draws on Derrida to suggest that a view of friendship 'as a relationship predicated on separation and difference allows for the accommodation of divergent opinion' as well as 'openness to change and development, and for spontaneity' $(2005,77)$. In these terms, friendship has the potential to break us out of the homogeneity of our existence, as suggested by Badhwar, who argues that the 'socially and politically subversive potential of friendship can be an important counterweight to the power of coercive communities' $(1993,34)$. Working with Dolly on the archive enabled me to form a depth of attachment to someone whom I would not have met through my usual patterns of social interaction, and as a result we crashed through a few social boundaries. Most significantly, in positively seeking out emotional attachment, I see our resulting friendship as presenting a challenge to the impoverishment of the relational fabric existing in and around both professional and academic work.

\section{Dolly - on transparency}

The enactment of the role of 'researcher' or 'academic' has to take a backseat to being human, which sounds vague and fluffy, but is enacted in practical ways. I think any participatory process has to be transparent, even if there are marks or stains of power and control occasionally smudging that transparency, because that's the whole point: to see why, how and when it is marked by inequality.

\section{Anna - on negotiating disparity in positions and privilege}

As I have sought to draw out through my reflections, the development of our friendship has been beneficial in its ability to overturn and address aspects of asymmetry in our relationship. Notably, in relation to equaling the levels of personal disclosure flowing between us. However, the value of our friendship also lies in the fact that it provided a robust, stable and strong space for acknowledging and confronting the ongoing disparities in our respective positions and privileges which ran through our shared participatory practice and research. I experienced these disparities in position and privilege as what Cresswell and Spandler describe as 'lived contradictions' $(2013,146)$ which come with politically engaged research that seeks to build solidarity on the one hand, whilst maintaining a foothold in academia on the other. Cresswell and Spandler surface these lived contradictions as (1) agent verses object (2) solidarity verses recuperation and (3) theory verses experience $(2013,143)$.

(1) Agent verses object surfaces the ever present temptation inherent in academic work to turn the individuals we work alongside into objects rather than critical agents, particularly when the notion of an 'interpretative responsibility' (Lather 2007,58 ) is so deeply embedded in academic frameworks. (2) Solidarity verses recuperation articulates how the compelling desire for solidarity with the individuals we work alongside sits in tension with what can be an equally compelling desire for individual recuperation and reward from within the academic field. This desire is partly motivated from the need for economic survival but is also caught up in the 'lures' of hegemonic prestige. The pursual of 'impact factors' and 'esteem indicators' associated with building an academic career (Cresswell and Spandler 2013,143) can often result in recycling the knowledge gained from engagement with others predominantly for selfish ends. (3) Theory vs. experience surfaces the tendency in academic work to construct and place a theoretical framework over and above the experiential knowledge production of the individuals we work alongside.

From within the Psychiatric Survivor movement, Russo and Beresford sum up the specificities of these tensions from their perspective in the following terms: 
In the psychiatric encounter: you give your story, you receive a diagnosis. This unequal, often non-transparent and also dishonest exchange goes beyond individual treatment situations and persists in most academic research work about us and our narratives. We often find ourselves giving not just our story but also the knowledge that has emerged from our experiences only to have it re-framed, serving various purposes and different agendas, and ultimately alienated from us. The fact that these encounters with interested academics happen outside treatment, and that the new interpretation usually makes more sense than the psychiatric one, hardly prevents us from feeling like somebody's case again. $(2015,153-$ 154)

In relation to 'agent vs. object' I have felt this tension in relation to the knowledge production contained in $\mathrm{my} \mathrm{PhD}$ thesis where the positioning of the contributors in my thesis, under my voice, has been an unavoidable consequence of the singular authoritative author model that underpins PhD frameworks.

In relation to the second lived contradiction brought out by Cresswell and Spandler (2013), I would suggest that the need for academic recuperation is, in a sense, exactly what my PhD research has been about. It is using the knowledge from the process to gain a doctorate to further my academic career. My position as the academic in the project, whether cloaked in participatory rhetoric or not, has bought with it a set of uncomfortable asymmetries between the contributors and myself connected into cultural, symbolic and economic capital. One example of this is in relation to how my status as the 'academic' translates into immediate economic gain. I entered the process with a Collaborative Doctoral Award with a bursary attached; whereas Dolly, Peter, Andrew and Stuart have been expected to contribute their knowledge and time with only expenses reimbursed. This sits in direct tension with the tenets of participatory practice, which 'calls for more relevant, morally aware and non-hierarchical practice which engages with equity to a greater degree' (Pain 2004, 652). Recognition of the gulf in our degrees of privilege, inscribed through and in the Western academic framework, has prompted me to surface, question and push against these insidious inequalities wherever possible in the process.

In relation to the third lived contradiction 'theory vs. experience' that tension is echoed right here in this article as Dolly's succinct perspectives, drawn directly from our shared experience fight for space against my more expansive theoretical framings that seek to give our experience legitimacy in the eyes of this audience by placing it in the context of broader academic discourse.

To be an engaged academic taking a participatory approach is to act with and in the possibility that in striving towards equity, the distance and difference that I/we are so desperate to overcome may in fact be entrenched, reinforced and reinscribed within and because of participatory intentions. This contradiction is surfaced by writers such as Leeuw, Cameron, and Greenwood (2012), who express concern that the claim advanced by participatory researchers that the line between researcher and researched is blurred, or even upended through participatory practice is always an ongoing falsehood. Drawing on Ahmed (2000), who surfaces a range of concerns in regards to the claims of collaborative ethnographic practice, Leeuw et al. suggests that hierarchical distance and difference is in fact continually 'reinscribed through acts that purport to merge subjects who occupy different positionalities' $(2012,186)$. Ahmed's argument is that any narrative of overcoming relations of authorisation in traditional research constitutes another form of authorisation $(2000,56)$, as it is the researcher who is praised for giving up authority. For Ahmed 'any act of authoring research framed in participatory and collaborative language risks reinforcing the distance between subjects precisely by naming that distance as overcome' $(2000,56)$. These are the 'complex, multidimensional, intractable, dynamic problems' (Kindon, Pain, and Kesby 2009, 91) associated with deep 
engagement in participatory research. Confronting these tensions, acknowledging them, critically reflecting on them together, and finding a joint pathway through them requires the kind of robust and stable relation that we fostered through our friendship.

\section{Dolly - on negotiating disparity in positions and privilege}

Our collaboration started out with obvious economic disparity: Anna had a bursary; myself and the other contributors received expenses. This has to change. To revolutionise that is to transform the culture. One of the most beautiful things Anna did was not merely critique disparity, but challenge it by refusing to speak at conferences and events about the research unless one of the contributors could be beside her. If all academics and professionals did that, whatever field it is, the approach to equality would come quicker than talking about it. I acknowledge that systems, politics, and worry about jobs and mortgages make it difficult, but I am willing and able to speak for myself if you give me a platform. It has to now come from you.

\section{Reflective conclusions}

Anna - In acknowledging that a move towards friendship became an important aspect of our approach to joint inquiry I seek to advocate for its value. In participatory practice and research that seeks to embrace processes of co-reflection as a means of addressing and, where possible, transforming asymmetries in position and privilege between participants there is a need to create safe and robust relational spaces that can handle frank, open and (at times) confrontational interpersonal exchanges. Our movement into friendship enabled such a space to develop between us. Our friendship did not in itself resolve these asymmetries, but rather it provided the necessary space for articulation, negotiation and challenge in regards to our different positions and privileges, and the impetus to push back as much as possible against the insidious inequalities that circulated through our participatory practice and research. Some may find the acknowledgement of our move towards friendship predicated on a personal and affective bond uncomfortable, and view it as a dangerous move. I fully acknowledge that the boundaries around all research relationships need careful consideration and negotiation. I re-iterate that there is no 'one size fits all' approach to finding where those boundaries should lie and that much depends on the research context, and the levels of experience of those involved. I recognise and advocate for the importance of strong ethical oversight, and in particular, would point to the value of the $\mathrm{PhD}$ supervisory role in enabling additional layers of interrogation and challenge over the direction of our developing relationship. I do not advocate that friendship is necessary or appropriate in all participatory relationships, rather that friendship as an aspect of a participatory process is valid and beneficial in specific contexts such as ours. Friendship as a relation that develops over time cannot be assumed, demanded or perused at the beginning of a process of co-inquiry. However, in appropriate contexts, where it emerges though the rhythm of practice and research through the ongoing negotiation of relational boundaries, it can be embraced and acknowledged, rather than feared or obscured. In opening out our experience, I seek to contribute to existing articulations on friendship as a method of inquiry (Tillmann-Healy 2003) and would like to see the emergence of a larger body of knowledge on the complexities, benefits, challenges and rewards of friendship as an aspect of co-inquiry.

As is the case with all relational stances bound up in practice and research, there are complexities and challenges around enabling friendship to flourish within processes of co-inquiry. The line that is walked when drawing the boundaries around levels of interpersonal disclosure, and the extent to which these are pushed on and moved during processes of co-inquiry, is an issue that in itself requires continual critical reflection. 
Stacey (1988) writing from the perspective of feminist ethnography focuses on the fine line that is walked in research that embraces capacities such as intuition, empathy and relationship in the quest for egalitarian research processes characterised by authenticity, reciprocity and inter-subjectivity. My description of our enactment of 'deep engagement' is in keeping with Stacey (1988) description of the potential rewards and difficulties engendered in adopting a deep relational approach. Dolly and I were able to give to each other 'practical and emotional support' coupled with 'comparatively non-judgmental acceptance', meaning that we came to value our relationship 'deeply' (Stacey 1988, 26). Yet because of this commitment, desertion would be felt equally as strongly, and therefore there is no easy way in which either of us can walk away. The friendship we have chosen to enact is therefore a form of opportunity and constraint. We are bound into it - we reap its benefits, but equally and at the same time we are tied into the bond. Our move into friendship demands and requires a long term commitment to each other, beyond the formal end of the practice and research surrounding the mental health recovery archive, on into the future. Given this reality, any embrace of friendship emerging from participatory practice and research is not to be taken lightly.

Bound up in recognising friendship as opportunity and constraint is the realisation that to be intimately involved to the point of friendship with those we research alongside also carries with it a question of capacity: there is a limit to the number of people we can hold close, and be committed to. This is the irreducible tension underlying friendship driven practice and research: to claim friendship, intimacy and relational depth is an act that draws the lines of inclusion around a handful, a select few. There is no way round the question of capacity that underpins and guides claims to friendship. It is a form of relating and conducting co-inquiry that names, chooses, and privileges the few (Derrida 1997).

As an academic who is an active participant in the recordkeeping field, I would like to draw out here how this exploration of friendship as a relational stance for enabling participatory co-inquiry fits more broadly into emerging epistemological approaches in my field where, over the last decade, there has been a growing number of academics adopting participatory approaches. The postmodern renegotiation of the relationship between archives, knowledge and power and an increasing emphasis on the relations between the archival record, social justice and human rights has led to growing usage of participatory techniques by recordkeeping professionals and academics as a means of standing alongside marginalised individuals and communities and facilitating joint developments in archival practice and research ${ }^{8}$ (e.g. Russell 2005; Faulkhead et al. 2007; Allard and Ferris 2015; Evans et al. 2015). At the same time, there is growing interest in exploring the social and relational aspects of recordkeeping alongside the systemic and structural, with a growing body of work approaching records and archives through an affective lens (Cifor and Gilliland 2016). My reflections seek to bridge and speak into this nexus in my field by providing an affective and relational exploration of a participatory process. To more fully understand what it means for archivists and recordkeepers to be 'participatory' we must move our knowledge production around the 'participatory' beyond a focus on the instrumental and structural, towards a more nuanced examination that unravels the social, relational and affective underpinnings of this kind of practice and research.

\footnotetext{
${ }^{8}$ There is resonance between the issues, context and participatory stance emerging from my PhD work around archival representation of mental health, and current research emerging from an Australian recordkeeping context around rights and representation of former and current children in care. In particular the ongoing ARC Future Fellowships Research of Dr Joanne Evans 'Connecting the Disconnected: Designing Socially Inclusive, Integrated, Archival and Recordkeeping Systems and Services' and Evans et al. 'Rights in Records by Design'.
} 
Dolly - The objective lens burns amidst its very evident coldness. It hurts. Psychiatry views the most subjective of experiences through an objective eye, and so much damage is done as a result. Psychiatry only perceives sickness in speech and behaviour. It is rare that a person tells the whole of their story to a psychiatrist, which goes beyond symptoms and pathology, even if they have spent decades in the mental health system. This makes the patient feel not listened to, invalidated, violated, a non-person. What do you think the response would be if research took the same tack? Academic standards of rigour are constructed to exclude and disallow certain sectors of society to participate with full voice in their own stories or transmission of their narratives. We are not passive recipients of our own history. Our sense-making of our stories doesn't belong to scholars, whose privileged access to academia push us out of our own picture. I wonder how many academics have been under the objectification they rate so highly? If Anna had taken a standard approach, remaining distant and impersonal, I am sure she would have gleaned useful information, but she would only have got about $10 \%$ of me. She would not have touched the depth of my experience, she would not have got to know the real me. She would have got the story of the mask I present to the world, and nothing of the person behind it. Talking about mental health and its potential causes can elicit profound and painful shame. How could I even begin to disclose around that without the equality of honesty, openness and shared lives. It would have been like walking down the same path but with the researcher being carried on a comfortable pedestal beside me. Let's not beat about the bush: current research methodologies offer privilege and power to the researcher, and what can that do to the person on the other end of that research except disempower and disadvantage? I did not have that experience with Anna. She tried her best to remove privilege and power in the dynamics of our relationship. It made it a much safer space. If you want to know the truth of a person, you have to share some of your truth too, and stop hiding behind the walls that protect you but not the person being researched. Research and academia alienates, and is a razor wrapped in power and privilege, something has to change. Of course, friendship as methodology is not for every research setting, or for every person you meet in research, but for me, in this study, it was the best process for me to tell my story unhindered and more truthful than it has ever been before whilst being a research participant. I have valued our continued friendship beyond the study. A shared personal journey is so rich, so deep, so elevating, it leaves the impersonal journey rigid and out in the cold. Why would I prefer the latter?

\section{Notes on contributors}

Anna Sexton has trained as a professional archivist and has had several roles in the archival field including managing the archives service for the City of Peterborough. She has recently completed a $\mathrm{PhD}$ in the Department of Information Studies at University College London where she is currently working as a Research Associate. Her PhD research explores participatory approaches to building life history archives in the context of mental health. Her PhD writing is autoethnographic and seeks to unravel and trace the complex threads of power, authority and control that run through participatory processes. Her PhD research speaks into the broader questions around archival endeavours approached within a social justice framework as well as offering some specific insights into archival work that seeks to document mental health from the perspective of the individual with lived experience.

Dolly Sen is a writer, artist, film-maker, mental health consultant and trainer, with lived experience of what has been labelled by the system as psychosis, mood disorder and PTSD. Her training and public speaking has taken her to The World Health Organisation in Geneva and to over 100 academic, charity, corporate and statutory organisations. She has written over ten books including autobiographies entitled The World is Full of Laughter and Am I still Laughing? and contributed 
chapters to over 20 other books including Encounters With Suicide. Dolly has made over 30 media appearances on TV, Radio, Internet and Print. Her other mental health work involves consultancy, key note speaking, coaching, research, group facilitation, campaigning, social media and creative work.

\section{References}

Ahmed, S. 2000. "Who Knows? Knowing Strangers and Strangeness." Australian Feminist Studies 15: 49-68. doi:10.1080/713611918.

Allard, Danielle, and Shawna Ferris. 2015. "Antiviolence and Marginalized Communities: Knowledge Creation, Community Mobilization and Social Justice through a Participatory Archiving Approach." Library Trends 64 (2): 360-383. doi:10.1353/lib.2015.0043.

Badhwar, Neera Kapur. 1993. Friendship: A Philosophical Reader. London: Cornell University Press. Baier, Annette. 1986. “Trust and Antitrust.” Ethics 96 (2): 231-260. doi:10.1086/292745.

Baum, Fran, Colin MacDougall, and Danielle Smith. 2006. "Participatory Action Research." Journal of Epidemiology \& Community Health 60 (10): 854-857. doi:10.1136/jech.2004.028662.

Billies, Michelle, Valerie Francisco, Patricia Krueger, and Darla Linville. 2010. "Participatory Action Research. Our Methodological Roots." International Review of Qualitative Research 3 (3): 277-286.

Christopher, Suzanne, Vanessa Watts, Alma Knows His Gun McCormick, and Sarah Young. 2008. "Building and Maintaining Trust in a Community-based Participatory Research Partnership." American Journal of Public Health 98 (8): 1398-1406. doi:10.2105/AJPH.2007.125757.

Church, Kathryn. 1995. Forbidden Narratives: Critical Autobiography as Social Science. London: Taylor \& Francis Publishing.

Cifor, Marika, and Anne Gilliland. 2016. "Affect and the Archive, Archives and Their Affects: An Introduction to the Special Issue." Archival Science 16 (1): 1-6.

Cresswell, Mark, and Helen Spandler. 2013. "The Engaged Academic: Academic Intellectuals and the Psychiatric Survivor Movement." Social Movement Studies 12 (2): 138-154.

doi:10.1080/14742837.2012.696821.

Delhi, K. 1991. "Leaving the Comfort of Home: Working through Feminisms." In Unsettling Relations: The University as a Site of Feminist Struggles, edited by Himani Bannerji, Linda Carty, Kari Delhi, Susan Heald, and Kate McKenna, 45-66. Toronto: Women's Press.

Derrida, J. 1997. Politics of Friendship. Translated by C. Collins. London: Verso.

Ellsworth, Elizabeth. 1989. "Why Doesn't This Feel Empowering? Working through the Repressive Myths of Critical Pedagogy." Harvard Educational Review 59 (3): 297-325.

Eyburn, R., and S. Ladbury. 1995. "Popular Participation in Aid Assisted Projects: Why More in Theory than in Practice?" In Power and Participatory Development, edited by N. Nelson and R. Wright, 7298. London: IT Publications.

Faulkhead, Shannon, Lynettte Russell, Diane Singh, and Sue McKemmish. 2007. "Is Community Research Possible within the Western Academic Tradition?" In Researching with Communities: Grounded Perspectives on Engaging Communities in Research, edited by R. DeSouza and A. Williamson, 39-55. Auckland: Muddy Creek Press. 
Freire, Paulo. 1972. Pedagogy of the Oppressed. Harmondsworth: Penguin.

Freire, Paulo. 1976. Education: The Price of Freedom. London: Writers and Readers Publishing Cooperative.

Hailey, J. 2001. "Beyond the Formulaic: Process and Practice in South Asian NGOs." In Participation: The New Tyranny?, edited by Bill Cooke and Uma Koothari, 88-101. London: Zed Books.

Han, Ju Hui Judy. 2010. "Neither Friends Nor Foes: Thoughts on Ethnographic Distance." Geoforum 41 (1): 11-14. doi:10.1016/j.geoforum.2009.09.007.

Heckler, Serena, and Andrew Russell. 2008. "Emotional Engagement in Strategic Partnerships: Grassroots Organising in a Tobacco Control Partnership in the North East of England." Evidence \& Policy: A Journal of Research, Debate and Practice 4 (4): 331-354.

Holton, Richard. 1994. "Deciding to Trust, Coming to Believe." Australasian Journal of Philosophy 72: 63-76. doi:10.1080/00048409412345881.

Jones, Karen. 1996. "Trust as an Affective Attitude." Ethics 107 (1): 4-25. doi:10.1086/233694.

Kesby, M. 2005. "Retheorizing Empowerment through Participation as a Performance in Space: Beyond Tyranny to Transformation." Signs: Journal of Women in Culture and Society 30 (4): 20372065. doi:10.1086/428422.

Kindon, S., R. Pain, and M. Kesby. 2009. Participatory Action Research Approaches and Methods. London: Routledge.

Lather, Patti. 2007. Getting Lost: Feminist Efforts toward a Double(d) Science. Albany: State University of New York Press.

Leeuw, Sarah De, Emile Cameron, and Margo Greenwood. 2012. "Participatory and Communitybased Research, Indigenous Geographies, and the Spaces of Friendship: A Critical Engagement." The Canadian Geographer 56 (2): 180-194. doi:10.1111/j.1541-0064.2012.00434.x.

Lugones, Maria C., and Elizabeth Spelman. 1983. "Have We Got a Theory for You! Feminist Theory, Cultural Imperialism and the Demand for 'The Woman's Voice'." Women's Studies International Forum 6 (6): 573-581. doi:10.1016/0277- 5395(83)90019-5.

Lykes, M. B., and E. Coquillon. 2007. "Participatory and Action Research and Feminisms: Towards Transformative Praxis." In Handbook of Feminist Research: Theory and Praxis, edited by Sharlene Hesse-Biber, 297-326. Thousand Oaks, CA: Sage.

Lynch, Sandra. 2005. Philosophy and Friendship. Edinburgh: Edinburgh University Press.

Mentinis, Mihalis. 2015. "Friendship: Towards a Radical Grammar of Relating." Theory \& Psychology 25 (1): 63-79. doi:10.1177/0959354314548887.

Moosa-Mitha, M. 2005. "Situating Anti-oppressive Theories within Critical and Difference-centered Perspectives." In Research as Resistance: Critical, Indigenous and Anti-oppressive Approaches, edited by Linda Brown and Susan Strega, 37-72. London: Canadian Scholars' Press.

Mouffe, Chantal. 1992. Dimensions of Radical Democracy: Pluralism, Citizenship, Community. London: Verso. 
Nickel, Phillip. 2007. "Trust and Obligation-Ascription." Ethical Theory and Moral Practice 10: 309319. doi:10.1007/s10677-007-9069-3.

Pain, Rachel. 2004. "Social Geography: Participatory Research." Progress in Human Geography 28 (5): 652-663. doi:10.1191/0309132504ph511pr.

Rawlins, W. K. 1992. Friendship Matters: Communication, Dialectics, and the Life Course. New York: Aldine de Gruyter.

Reason, Peter, and Hilary Bradbury, eds. 2001. Handbook of Action Research: Participative Inquiry and Practice. London: Sage.

Rockhill, K. 1987. "The Chaos of Subjectivity in the Ordered Halls of Academe." Canadian Woman Studies 8 (4): 12-17.

Russell, Lynette. 2005. "Indigenous Knowledge and Archives: Accessing Hidden History and Understandings.” Australian Academic \& Research Libraries 36 (2): 161-171.

doi:10.1080/00048623.2005.10721256.

Russo, Jasna, and Peter Beresford. 2015. "Between Exclusion and Colonisation: Seeking a Place for Mad People's Knowledge in Academia." Disability \& Society 30 (1): 153-157.

doi:10.1080/09687599.2014.957925.

Sexton, Anna. 2016. Archival Activism and Mental Health: Being Participatory, Sharing Control and Building Legitimacy. PhD diss.: University College London.

Spandler, Helen, and Theo Stickley. 2011. "No Hope without Compassion: The Importance of Compassion in Recoveryfocused Mental Health Services." Journal of Mental Health 20 (6): 555-566.

Stacey, Judith. 1988. "Can There Be a Feminist Ethnography?" Women's Studies International Forum 11 (1): 21-27. doi:10.1016/0277-5395(88)90004-0.

Tillmann-Healy, Lisa. 2003. "Friendship as Method." Qualitative Inquiry 9 (5): 729-749. doi:10.1177/1077800403254894.

Weiss, Robert S. 1998. "A Taxonomy of Relationships." Journal of Social and Personal Relationships 15: 671-683. doi:10.1177/026540759881556006. 